\title{
An Association between Fasting Blood Glucose level and BMI in BICH Young Adult Students: A study in a Tertiary Care Hospital, Dhaka, Bangladesh
} Dr. Nilufa Akhter ${ }^{1 *}$, Bilquis Banu ${ }^{2}$, Dr. Salma Sadia ${ }^{3}$

\footnotetext{
${ }^{1}$ Professor, Department of Physiology, Bangladesh Institute of Child Health (BICH), Dhaka Shishu (Children) Hospital, Dhaka, Bangladesh

${ }^{2}$ Professor, Department of Pathology, Bangladesh Institute of Child Health (BICH), Dhaka Shishu (Children) Hospital, Dhaka, Bangladesh

${ }^{3}$ Assistant Professor, Department of Biochemistry, Bangladesh Institute of Child Health (BICH), Dhaka Shishu (Children) Hospital, Dhaka, Bangladesh
}

Background: Non-communicable disease like diabetes is becoming a public health problem that it is already present in most middle-low income countries. The increased risk of associated with high BMI levels in middle-aged group has been clearly established but young adult age group yet not known. So, the aim of this study was to determine the relationship between body mass index (BMI) and fasting blood glucose level in young adult age group. Objectives: To observe fasting blood glucose level in young adult students of Bangladesh institute of child health (BICH) \& its association with BMI. Materials \& Method: This cross sectional study was carried out on 127 young adult students aged 18-32 years in the department of physiology, Bangladesh institute of Child health (BICH) from January 2018 to January 2019. Methods: Fasting blood glucose of the study subjects were measured by using blood glucometer (using blood glucose test strip). BMI was calculated as weight $(\mathrm{kg}) / \mathrm{height}(\mathrm{m} 2)$. Results: The study result found that $14.96 \%$ of the participants are underwweight group, $26.77 \%$ are overweight group and $16.54 \%$ are obese group. Mean glucose level $5.411 \pm 0.4806$ in underweight group (BMI<18.5), Within the overweight group (BMI 23-24.99) mean glucose level is $5.597 \pm 0.6548$. The obese group (BMI $\geq 25$ ) mean glucose level is $5.638 \pm 0.6756$. Though mean glucose level are within normal range but positive correlation ( $\mathrm{p}$-value $=0.324$ ) between BMI and blood glucose levels were found. The mean plot in Anova analysis shows that there is a substantial change of the mean in glucose level within the underweight and the overweight and obese group. Ordinal regression analysis further shows that the difference is significant (p value=0.004). Conclusion: Positive correlation were found between BMI and fasting glucose level. BMI which is non-invasive is recommended as a screening tool for developing diabetes risk and recommending early measure to control the glucose level.

Keywords: Body Mass Index (BMI), Blood Glucose Level (BGL).

Copyright @ 2020: This is an open-access article distributed under the terms of the Creative Commons Attribution license which permits unrestricted use, distribution, and reproduction in any medium for non-commercial use (NonCommercial, or CC-BY-NC) provided the original author and source are credited.

\section{INTRODUCTION}

The body mass index (BMI) is used to categorize adults into different groups based on anthropometric height/weight characteristics. BMI represents an index of an individual's fatness. BMI is generally used as an indication for the development of or prevalence of numerous health problems [1]. One of the most common health hazards worldwide is diabetes, which is the presence of excessive sugar in the blood. Diabetes can lead to several health complications in the long run. Diabetes is a non-communicable disease which has caused substantial mortality and morbidity worldwide and significant economic impact [2, 3]. BMI is a widely used risk factor for diabetes. ADA recommends "BMI Cut Points to Identify At-Risk Asian Americans for Type 2 Diabetes Screening" (32,33) suggest that the BMI cut point should be lower for the
Asian American population. The BMI cut points fall consistently between 23 and $24 \mathrm{~kg} / \mathrm{m} 2$ (sensitivity of $80 \%$ ) for nearly all Asian American subgroups (with levels slightly lower for Japanese Americans). This makes a rounded cut point of $23 \mathrm{~kg} / \mathrm{m} 2$ practical" [4]. According to WHO 422 million people worldwide had diabetes, with a major concentration in the developing countries and $80 \%$ of diabetes death take place in low and middle-income countries. Diabetes is gradually becoming a common health issue in Bangladesh. In Bangladesh, with it's growing population, a recent meta-analysis showed that there is a significant increase in diabetes among adults. It has sharply increased from $4 \%$ in 1995 to 2000 and $5 \%$ from 200 to 2005 to $9 \%$ in 2006 to 2010.5 . The prevalence will be $13 \%$ by 2030 According to the International Diabetes Federation [5, $6]$. 
In addition to the issue of diabetes, another study shows the increasing problem of underweight and overweight/obesity in Bangladesh among older adults $(\geq 35)$. However, underweight remains the major public health issue for both female and males $(\geq 35)$ which include $30 \%$ of the population. Both conditions are related to the increased danger of morbidity and mortality with the risk of developing noncommunicable diseases. ${ }^{7}$ In our study, we present the prevalence and socio-demographic determinants of underweight, overweight and obesity among the youngadult population aged $\leq 32$ years.

\section{OBJECTIVES}

To evaluate the blood glucose level of young adult students in Bangladesh institute of child health $(\mathrm{BICH}) \&$ its association with BMI.

\section{Materials ANd Methods}

The study was carried out on 127 young adult students aged 18-32 years in the department of physiology, Bangladesh institute of Child health (BICH) from January 2018 to January 2019. One hundred and twenty seven(127) healthy young consenting adults between the ages of 16 and 32 years were selected for the study.

\section{Measurement of fasting blood glucose level}

Fasting early morning blood glucose of the study subjects were measured using blood glucometer (using blood glucose test strip). For the test a small volume of blood samples were collected by piercing finger tips of the study subjects using sterile lancet .

\section{Blood Glucose Determination}

Fasting plasma glucose level range was based on the recommendation of WHO.

\section{Body Mass Index (Bmi) Estimation}

Weights were taken to the nearest $\mathrm{lb}$ and height to the nearest feet from which BMI was calculated as weight $(\mathrm{kg}) /$ height $(\mathrm{m} 2)$.

\section{Statistics}

The researcher used simple statistical tools to analyze the data. The association between Glucose level and BMI among the groups was checked through pvalues using SPSS version 24. For analytical tests, a $95 \%$ confidence limit $(\mathrm{p}<0.05)$ was taken as the level of significance. We also performed a regression analysis.

\section{RESULTS}

The study result found that $14.96 \%(n=19)$ of the participants are underweight $(\mathrm{BMI}<18.5), 26.77 \%$ $(\mathrm{N}=34)$ of the participants are overweight (BMI 23$24.99)$ and $16.54 \%(n=21)$ of the participants are obese (BMI >25). (Table-2) Among the groups, the underweight $(\mathrm{BMI}<18.5)$ mean glucose level is, 5.411 \pm 0.4806 , normal-weight group (BMI 18.5-22.9) mean

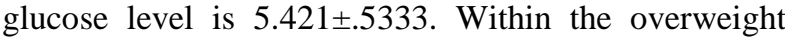
group (BMI 23-24.99) mean glucose level is $5.597 \pm 0.6548$. The obese group (BMI $\geq 25)$ mean glucose level is $5.638 \pm 0.6756$. $45.40 \%(n=44)$ of nondiabetic participants (5.6) belongs to the normal BMI group, $29.60 \%(n=8)$ pre-diabetic (5.6-6.99) participants belong to normal and overweight BMI group equally and $33.33 \%(n=1)$ diabetic participants $(\geq 7)$ belong to normal, overweight and obese BMI group equally. (Table-3). There is a positive correlation ( $\mathrm{p}$ value $=0.324$ ) between BMI and blood glucose levels. (Figure-1) The mean plot in Anova analysis shows that there is a substantial change of the mean in glucose level within the first category(non-diabetes) and the second category(prediabetes and diabetes). (Figure2) Ordinal regression analysis further shows that the difference is significant $(\mathrm{p}$ value $=0.004$ )

Table-1: Demographic Distribution of the study participnts (n=127)

\begin{tabular}{|l|l|l|l|}
\hline Age & Number (\%) & Min, Max & Mean \pm SD \\
\hline $\mathbf{1 6 - 2 0}$ & 45 (35.4) & \multirow{3}{*}{18,32} & \multirow{2}{*}{$21.48 \pm 2.218$} \\
\cline { 1 - 2 } $\mathbf{2 1 - 2 5}$ & $79(62.2)$ & & \\
\hline $\mathbf{2 2 6}$ & $3(2.4)$ & & \\
\cline { 1 - 2 } Sex & & & \\
\cline { 1 - 2 } Male & 63(49.6) & & \\
\cline { 1 - 2 } Female & 64(50.4) & & \\
\hline
\end{tabular}

Table-2: Blood Glucose level within BMI group ( $n=127)$

\begin{tabular}{|l|l|l|l|l|l|}
\hline BMI & $\mathbf{N}(\%)$ & Mean & SD & Min. & Max. \\
\hline Underweight & $19(14.96)$ & 5.411 & .4806 & 4.1 & 6.1 \\
\hline Normal & $53(41.73)$ & 5.421 & .5333 & 4.2 & 7.5 \\
\hline Overweight & $34(26.77)$ & 5.597 & .6548 & 4.8 & 7.9 \\
\hline Obese & $21(16.54)$ & 5.638 & .6756 & 4.8 & 7.2 \\
\hline Total & $127(100)$ & 5.502 & .5871 & 4.1 & 7.9 \\
\hline
\end{tabular}


Table-3: Diabetes Status in BMI Class ( $\mathrm{n}=127)$

\begin{tabular}{|l|l|l|l|l|}
\hline BMI & BGL & Diabetes & Pre-diabetes & Non-Diabetes \\
\hline Underweight & $\mathrm{N}(\%)$ & 0 & $5(18.50)$ & $14(14.40)$ \\
\hline Normal & $\mathrm{N}(\%)$ & $1(33.30)$ & $8(29.60)$ & $44(45.40)$ \\
\hline Overweight & $\mathrm{N}(\%)$ & $1(33.30)$ & $8(29.60)$ & $25(25.80)$ \\
\hline Obese & $\mathrm{N}(\%)$ & $1(33.30)$ & $6(22.20)$ & $14(14.40)$ \\
\hline Total & $\mathrm{N}$ & 3 & 27 & 97 \\
\hline
\end{tabular}

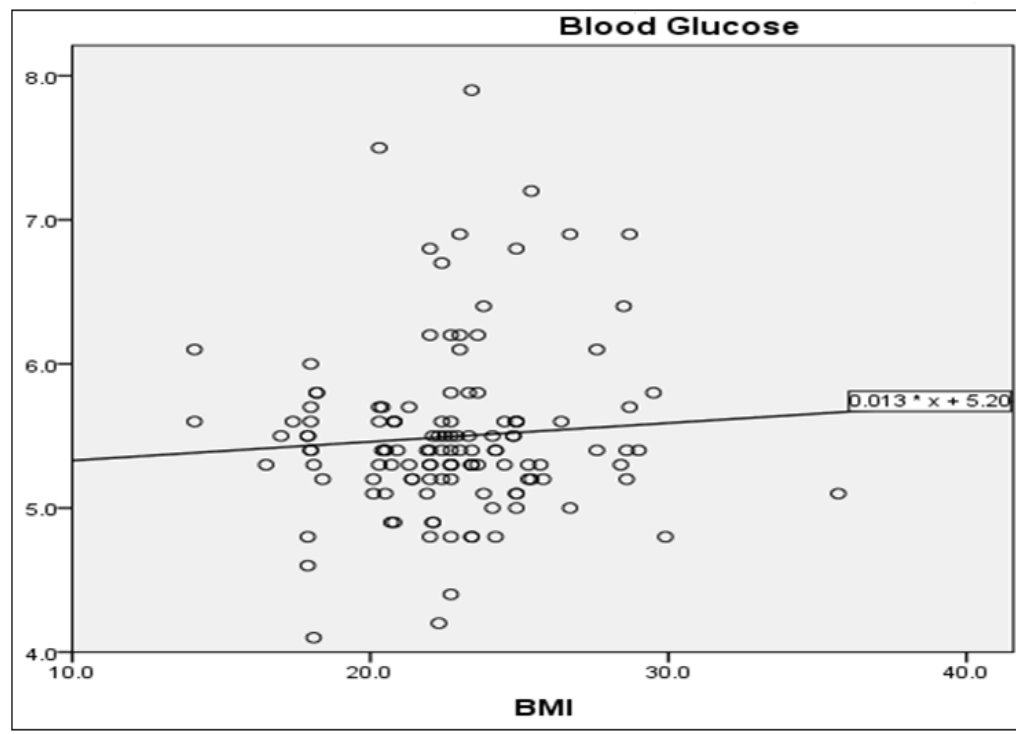

Fig-1: Correlation between BMI and Blood Glucose

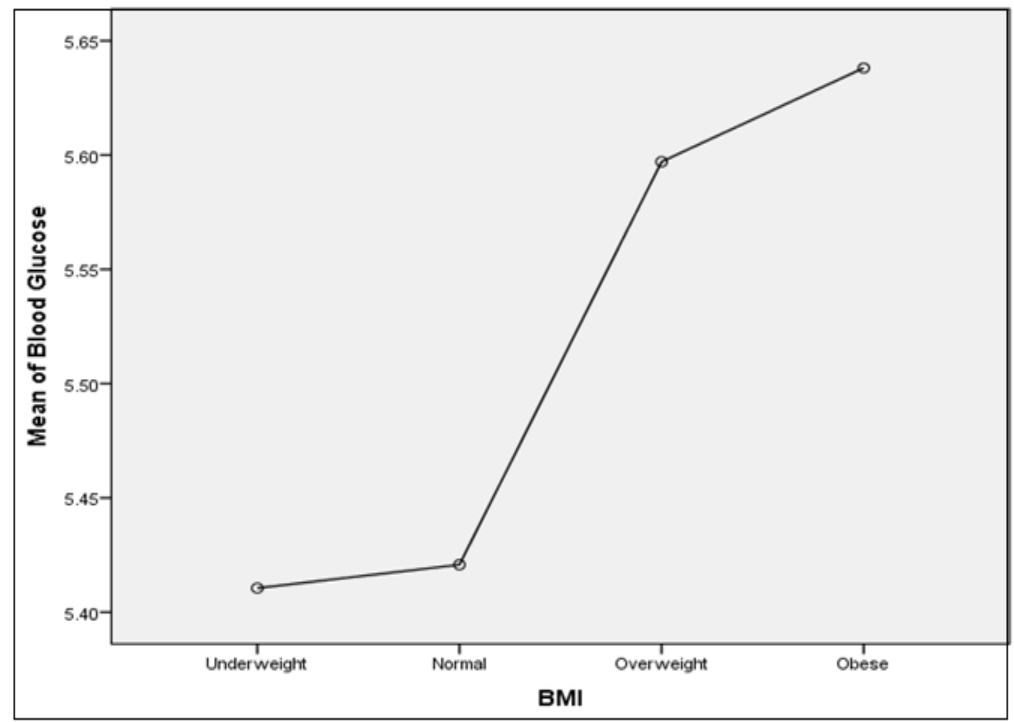

Fig-2: Mean plot of Blood Glucose (Ordinal regression analysis shows a $\mathrm{p}$ value $=0.004)$

\section{DISCUSSION}

It has been observed that Bengali young adults are highly prone to diabetes even with only modestly overweight, central obesity, which is observable in other studies based on Asian participants [8,9]. Our study revealed that a small number of participants were diabetic but a substantial percentage of subjects were pre-diabetic. For the study, all of our subjects were healthy young-adults within the age range 18-32. These findings correspond well with another cross sectional study on university graduates of Bangladesh public university [10]. In our study we found the mean glucose level drastically changes between the underweightnormal group and overweight-obese group ( $p$ value <.005) [11-13]. The positive but weak correlation between BGL and BMI is supported by other studies although, it found a stronger correlation between the two [14]. On the contrary, a recent study has found the mean BMI in those without diabetes was 26.8. In those with diabetes, the BMI was 29.1; that is, it was higher as generally expected. However, the percent of lean body mass was the same; that is, the increased BMI in those with diabetes was not due only to an excessive 
accumulation of fat [15]. Other factors that can contribute to developing overweight and obesity could be eating speed $[16,17]$. A study conducted on Chinese college students suggests that health education programs should be executed to help young-adults control their eating speed [18]. An increasing number of obese people among young adults can also result from lifestyle change such as leaving home, going to university/college, starting work, developing relationships, possibly cohabiting or marrying, potentially experiencing pregnancy and child-rearing [19-21]. Unhealthy lifestyle among young adults due to stress and sociological factors can make vulnerable [22, 23]. The finding on higher BMI is similar to other studies that found elevated BMI was related to greater rates of conversion to diabetes [24]. Participants in the underweights BMI group, possibly showing lower glucose levels, may have reduced secretion of glucagon and epinephrine, causing inadequate hepatic glucose production throughout iatrogenic hypoglycemia. Additionally, the result of glucagon may be compromised in people with insufficient glycogen since this hormone increases blood glucose level through hepatic glycogenolysis [25, 26].

\section{Limitations OF THE STUdy}

The study has a limited sample size and preferable it considers only the same group of people who particularly studies in BICH.

\section{CONCLUSION AND \\ RECOMMENDATIONS}

According to our information, a high prevalence of glucose level was ascertained among young adult students. It considers that overweight and obesity were considerably related to prehypertension and high blood pressure among young students in $\mathrm{BICH}$. This study showed that the impact of BMI on the fasting glucose level is negligible or too small to be clinically significant. Future studies should explore the other possible reason that can lead to the development of pre-diabetes among young adults. The study disclosed to focus on our body mass index and daily lifestyle.

\section{REFERENCES}

1. Nuttall FQ. Body mass index: obesity, BMI, and health: a critical review. Nutrition today. 2015 May;50(3):117.

2. Islam SM, Ferrari U, Seissler J, Niessen L, Lechner A. Association between depression and diabetes amongst adults in Bangladesh: a hospital based case-control study. Journal of global health. 2015 Dec;5(2):204-206.

3. Yip WCY, Sequeira IR, Plank LD, Poppitt SD. Prevalence of pre-diabetes across ethnicities: A review of impaired fasting glucose (IFG) and impaired glucose tolerance (IGT) for classification of dysglycaemia. Nutrients. 2017;9(11):1-18.

4. American Diabetes Association. 2. Classification and diagnosis of diabetes. Diabetes care. 2017 Jan 1;40(Supplement 1):S11-24.

5. Mohiuddin AK. Diabetes Fact: Bangladesh Perspective. Int J Diabetes Res. 2019;2(1):14-20.

6. Akter S, Rahman MM, Abe SK, Sultana P. Prevalence of diabetes and prediabetes and their risk factors among Bangladeshi adults: a nationwide survey. Bull World Health Organ. 2014;92(3):204-213A.

7. Biswas T, Garnett SP, Pervin S, Rawal LB. The prevalence of underweight, overweight and obesity in Bangladeshi adults: Data from a national survey. 2017; 51:1-12.

8. Singh RB, Niaz MA. Coronary risk factors in Indians. Lancet. 1995;346:778-779.

9. Nelson DL, Cox MM. Lehninger Principles of Biochemistry. 4th (ed), W.H Freeman and Company, New York. 2005.

10. Hossain I, Islam S, Hasan MR, Akter M, Khoka SH. Fasting blood glucose level and its association with sex , body mass index and blood pressure : a cross sectional study on a Bangladeshi public university students. 2017;4(8):2663-2669

11. Groheux D, Delord M, Rubello D, Colletti PM, Nguyen ML, Hindie' E. Variation of Liver SUV on 18 FDG- PET/CT Studies in Women With Breast Cancer. Clin Nucl Med. 2013; 38:422-425.

12. Sprinz C, Altmayer S, Zanon M, Watte G, Irion K, Marchiori E, Hochhegger B. Effects of blood glucose level on 18F-FDG uptake for PET/CT in normal organs: a systematic review. PloS one. 2018;13(2):8-19.

13. Gikas A, Sotiropoulos A, Pastromas V, Papazafiropoulou A, Apostolou O, Pappas S. Seasonal variation in fasting glucose and HbA1c in patients with type 2 diabetes. Prim Care Diabetes. 2009; 3:111-4.

14. Siegel D, Meier J, Maas C, Lopez J, Swislocki ALM. The Effect of Body Mass Index on Fasting Blood Glucose after Initiation of Thiazide Therapy in Hypertensive Patients. 2008; 21(4).

15. Smalley KJ, Knerr AN, Kendrick ZV, Colliver JA, Owen OE. Reassessment of body mass indices. Am J Clin Nutr. 1990; 52(3):405Y408.

16. Ford AL, Bergh C, Södersten P, Sabin MA, Hollinghurst S, Hunt LP, Shield JP. Treatment of childhood obesity by retraining eating behaviour: randomised controlled trial. Bmj. 2010 Jan 6;340.

17. Sonoda C, Fukuda H, Kitamura M, Hayashida H, Kawashita Y, Furugen R, Koyama Z, Saito T. Associations among obesity, eating speed, and oral health. Obesity facts. 2018;11(2):165-75.

18. Shan MJ, Zou YF, Guo P, Weng JX, Wang QQ, Dai YL, Liu HB, Zhang YM, Jiang GY, Xie Q, Meng LB. Systematic estimation of BMI: A novel insight into predicting overweight/obesity in undergraduates. Medicine. 2019 May;98(21). 
19. Butler SM, Black DR, Blue CL, Gretebeck RJ. Change in diet, physical activity, and body weight in female college freshman. Am J Health Behav. 2004; 28:24-32.

20. Burke V, Mori TA, Giangiulio N, Gillam HF, Beilin LJ, Houghton S, Cutt HE, Mansour J, Wilson A. An innovative program for changing health behaviours. Asia Pacific Journal of Clinical Nutrition. 2002 Dec;11:S586-97.

21. Linne Y, Dye L, Barkeling B, Rössner S. Weight development over time in parous women-the SPAWN study-15 years follow-up. International journal of obesity. 2003 Dec;27(12):1516-22.

22. Jekielek S, Brown B. The transition to adulthood: characteristics of young adults ages 18 to 24 in America. 2005; 1-41. Washington, DC, The Annie E. Casey Foundation, Population Reference Bureau and Child trends.
23. Poobalan AS, Aucott LS, Precious E, Crombie IK, Smith WC. Weight loss interventions in young people (18 to 25 year olds): a systematic review. [Review] [44 refs]. Obes Rev. 2010; 11:580-92.

24. Defina LF, Vega GL, Leonard PD, Grundy SM. Fasting Glucose, Obesity and Metabolic Syndrome as Predictors of Type 2 Diabetes: The Cooper Center Longitudinal Study. 2012; 60(8):11641168.

25. Winnick JJ, Kraft G, Gregory JM, Edgerton DS, Williams P, Hajizadeh IA, Kamal MZ, Smith M, Farmer B, Scott M, Neal D, Donahue EP, Allen E, Cherrington $\mathrm{AD}$. Hepatic glycogen can regulate hypoglycemic counterregulation via a liver-brain axis. Journal ofClinical Investigation, 2016;126:2236-2248.

26. Melmed S, Polonsky KS, Larsen PR, Kronenberg HM. Williams's textbook of endocrinology. 13th edition. Elsevier. 2016. 